\title{
Prazo de Ação Rescisória e Direito Intertemporal
}

\author{
Celso Neves \\ Titular de Direito Processual Civil da
}

Embora de interesse transitório, em face dos próprios dados de sua estrutura, o problema do prazo para propor-se ação rescisória - reduzido a dois anos pelo artigo 495, do C.P.C. de 1973 - tem dado margem a posições divergentes, da doutrina e dos tribunais, ora no sentido de que o direito de ajuizá-la, quando já em curso o respectivo tempo decadencial, subordina-se, desde logo, à lei nova, ora no de que pela revogada permanece regulado. A propósito do tema, em parecer, tivemos ensejo de manifestar nossa preferência por esta última alternativa, sublinhando, de início, a observação de Pontes DE MiRANDA, ao aludir à circunstância de que "grande parte dos direitos se conserva insubjetivada constituindo campo do direito objetivo puro, e outra parte subjetiva-se, mercê daquele plus" a que se referira - quando se reportara à subjetivação - para anotar, em seguida, a variação a que se sujeita, no tempo e no espaço, a "linha divisória entre os direitos subjetivos e os direitos não-subjetivos" e acrescentar: "Vulgarmente, exames desatentos confundem o direito subjetivo, a pretensão e a ação. A ação, a actio, supõe, sem necessitar, o direito objetivo, que a dê, e fato, que constitua a razão de seu exercício. Por isso mesmo não se identifica com o dever do sujeito passivo. Se o direito subjetivo tende à prestação, surgem a pretensão e a ação. A ação, que supõe haver-se transgredido a norma, constitui outro plus e tende, não à prestação, mas a efeito jurídico específico. $O$ credor tem direito subjetivo ao que se lhe atribui; tem-no, desde que a relação nasceu. A exigibilidade faz-lhe a pretensão. Se o devedor não paga como e quando deve pagar, cabe-lhe, então, a ação. Não se diga que a coação a caracteriza, nem que caracterize os dois, a ação e o 
direito subjetivo; porque o que existe de coativo no direito é comum ao direito objetivo não-subjetivo e aos direitos subjetivos". (Com. ao C.P.C. de 1973, Tomo I, págs. 121-122) "À medida que o direito subjetivo se acentua - anota, mais adiante, PONTES - se atualiza e se integra pelo advento de circunstâncias e condiciones juris, surgem as pretensões jurídicas." (Ob. e tomo cit., pg. 126) "O direito subjetivo, a pretensão e a ação preexistem ao exercício, ao uso dos remédios processuais. Se o direito do Estado $A$ confere a ação, mas o do outro não possui o remédio, o titular do direito subjetivo, da pretensão e da ação não pode, no outro Estado, provocar a Justiça. A ação não existe porque se vai exercer, condicionada à entrada do titular em juízo. Existe por sí, independente de qualquer manifestação de vontade do titular." (Ob. e tomo cit., pág. 136) Em síntese, segundo o magistério de PONTES DE MIRANDA, o "direito objetivo é a regra sobre as relações de direito e a sua eficiência, independente de qualquer subjetivação, exigibilidade ou acionabilidade", enquanto o "direito subjetivo marca toda aquela precisão, aquela localização, aquela individuação" (ob. e tomo cit., pág. 138) - cujas conseqüências ou operam segundo a própria normatividade daquele, ou mediante a tutela jurídica processual.

Percebe-se, a essa linha de raciocínio, que ação rescisória se insere nesta última categoria, pertencendo àquela normatividade que se efetiva pela tutela jurídica processual, inerente ao seu próprio conceito.

Se evoluiu, no fio histórico, o conceito de ação, a partir da conhecida fórmula de CELSO - nihil aliud est actio, quam ius, quod sibi debeatur, iudicio persequendi (Dig. 1.44, tit. 7, fr. 51) passando pelo direito medieval que procurou distinguir direito subjetivo e ação, vendo nesta um meio e não um direito, segundo a fórmula de HeINECCIUs - Actio... aut accipitur pro medio legitimo jus suum in judicio persequendi - já GLÜCK, aludindo a uma definição de CLAR - actio est remedium jus persequendi in judicio - considere-a deficiente, por não diferenciar a ação da exceção, afrontando, com isso, o texto de PAULo: actionis verbo non continetur exceptio (Lib. III, ad Editum). Depois, enunciando o seu próprio pensamento, diz GLÜCK: "Sicchè dicesi azione piuttosto un mezzo giuridico giudiziario, del quale io mi servo affinche altri sia condannato e dal giudice obbligato a darmi qualche cosa, che di pieno diritto io posso de lui pretendere. Dove l'eccezione si è un mezzo di giudiziaria difesa contro l'azione. Tanto con l'azione, quanto con l'eccezione, si 
perseguta, adunque, in giudizio il proprio diritto, ma certamente con uno scopo affatto diverso. Imperocchè la persecuzione giudiziaria del diritto, fatta mediante l'azione, mira a che il convenuto sia condannato a darsi qualque cosa. Laddove chi mediante una eccezione rechiama il suo diritto in giudizio, non ha che l'intenzione di leberarsi con tale mezzo, in tutto o in parte, per sempre o almeno per un certo tempo, dalla pretenzione dell'attore." (Pandectas, II, págs. 448-449)

Meio e remédio são, também, as qualificações de MeLLo FreIRE: "Actiones nos hic adcipimus non tamquam jura, quae nobis competunt, sed tamquam medium jus nostrum in judicio prosequendi" (Inst., Lib. IV, tit. VI, § 1). No § II escreve: "Actiones hoc est, remedia jus nostrum in judicio prosequendi".

Correa Telles, no $\S 10^{\circ}$ de sua Doutrina das Ações, define a ação como "remédio de direito para pedir ao juiz que obrigue outro a dar ou fazer aquilo de que tem obrigação perfeita"

A Plosz (1876) e Degenkolb (1877) cabe o mérito de haverem assentado a autonomia do direito de ação como direito público subjetivo do cidadão contra o Estado, à semelhança do que afirmara MUTHER. Observam eles que se o próprio vencido se tem como autorizado a promover a ação, para isso deve haver um fundamento jurídico que não está na lide, por eles relacionado ao direito de agir em juízo, direito subjetivo público, independente da afetiva existência de um direito privado. Daí sustentar DEGENKOLB que se deve encontrar, para a doutrina processual, uma base autônoma, objetiva, imparcial; uma base comum para a ação vitoriosa e não vitoriosa que não poderia estar no direito privado.

O dado essencial é ter, cada um o poder de convocar outros perante o juiz. Esse é o direito de agir que não tem caráter privado mas funda-se na própria personalidade. Esse direito preexiste à demanda judicial e com esta se exercita, cabendo a quem aluda a uma norma legal existente. DEGENKOLB erige a boa-fé do autor em condição do direito de ação. Posteriormente - Der Streit über den Klagerechtsbegriff, Leipzig, 1905 reconheceu que um direito de agir cabente a quem creia ter razão não é um direito subjetivo, mas uma simples faculdade jurídica, admitindo como ação um poder jurídico de obter contra o adversário um êxito favorável no processo, segundo observa ChIOVENdA (nota 39 à L'azione nel Sistema dei Diritti).

Segundo a conhecida análise de PEKELIS, a grande dissensão, na teoria moderna, gira em torno das seguintes questões: 
é a ação um elemento do direito subjetivo? é parte, momento ou posição dele? relativamente a isso, é um direito autônomo, acessório, instrumental, primário, secundário? Eis o complexo de questões, mediante cujas respostas, segundo PEKELIS, pode-se retomar o movimento de idéias em torno da ação, sobrelevando a relação com o direito subjetivo como o denominador comum de todas as doutrinas da ação.

$\mathrm{Na}$ terceira edição do Manuale, LIEBMAN, depois de rápida alusão aos precedentes histórico-científicos do conceito de ação e à distinção entre direito subjetivo substancial e ação, negando que esta compita, verdadeiramente, a todos, escreve: "è un diritto soggettivo diverso da quelli del diritto sostanziale, perchè rivolto verso lo Stato, senza essere diretto ad una sua prestazione: è piuttosto un diritto d'iniziativa e d'impulso, con cui il singolo pone in movimento l'esercizio di una funzione pubblica, dalla quale spera di ottenere la protezione delle proprie ragioni, disponendo a questo scopo dei mezzi apprestati dalla legge per farle valere (pur sapendo che l'esito potrá anche essergli sfavorevole); è dunque un diritto fondamentale dei singolo, che qualifica la sua posizione nell'ordinamento giuridico e nei confronti dello Stato, conferito e regolato dalla legge processuale, ma rafforzato da una garanzia constituzionale in cui troviamo scolpiti i suoi connotati essenziali." (Vol. I, página 120)

Quanto a nós filiamo-nos à corrente dominante que vê na ação direito autônomo, sem vínculo elementar com o direito subjetivo material, mantendo, com este, relação de instrumentalidade mediata. Topologicamente, pertence ao direito público, subjetivando-se, ativamente, em quem exige a tutela jurídica processual e, passivamente, no Estado que detem o poder-dever de prestá-la. Seu elemento objetivo, portanto, é essa tutela teleologicamente voltada, imediatamente, para a realização do direito objetivo e, mediatamente, para a efetivação do direito subjetivo do litigante.

À linha desses dados é que conceituamos a ação como direito público subjetivo de exigir do Estado a prestação de tutela jurídica processual, tendente à realização imediata do direito positivo e mediata do direito subjetivo, àquela correspondente.

Que a ação rescisória configure um direito subjetivo não se pode, pois, pôr em dúvida. Importa saber, entretanto, em que momento esse direito, como tal, se tem por adquirido.

Em nosso sistema jurídico, de lege lata, "consideram-se adquiridos assim os direitos que o seu titular, ou alguém por 
ele, possa exercer, como aqueles cujo começo do exercício tenha termo pré-fixo, ou condição preestabelecida inalterável, a arbítrio de outrém", segundo o enunciado do $\$ 2 .^{\circ}$, do art. $6^{\circ}$, da vigente Lei de Introdução ao Código Civil. Como acentua Clóvis, para "que o direito possa ser exercido pelo titular ou por seu representante, é necessário: a) que se tenha originado de um fato jurídico, de acordo com a lei do tempo, em que se formou ou produziu; b) que tenha entrado para o patrimônio do indivíduo. Assim a definição da lei, referida em primeiro lugar, pode ser convertida nesta outra: direito adquirido é um bem jurídico, criado por um facto capaz de produzí-lo, segundo as prescripções da lei então vigente, e que, de acordo com os preceitos da mesma lei, entrou para o patrimônio do titular." (Com., vol. I, ed. 1927, pág. 97)

$O$ direito de propor ação rescisória subjetiva-se no litigante vencido, como direito adquirido, no exato momento em que a sentença rescindenda transite em julgado. Desde então esse direito pode ser exercido, até que se consume - como elemento essencial, dele integrante - o prazo para isso estabelecido na lei que tenha regido a sua subjetivação e pela qual se regulará, também a limitação objetiva do iudicium rescindens. Lei superveniente que regule de maneira diversa a ação rescisória, seja quanto a seus pressupostos, seja quanto ao prazo, não se aplica, pois, às ações rescisórias que, anteriormente, já poderiam ter sido ajuizadas. É esse poder-ter-sido ajuizada antes da lei nova que lhe assegura a imutabilidade, ainda depois de disciplina nova - empiorante ou eliminativa - que, se for aplicada a configurações pretéritas, violará o § 3..$^{\circ}$ do art. 153, da Constituição da República.

Por isso a jurisprudência entende que o juízo rescisório vincula-se às hipóteses previstas na lei vigente ao tempo do trânsito em julgado da sentença rescindenda; por isso a própria eliminação da ação rescisória, por efeito de lei nova, não excluiria o ajuizamento e apreciação, segundo a disciplina da lei anterior, de ações rescisórias que, sob a sua vigência, se tornaram possíveis. 0 direito de propô-las nasce com o dies supremus que lhe é inerente. Alterá-lo será alterar o direito adquirido, em um de seus elementos essenciais, com ofensa à vedação constitucional.

Insista-se nisto : o direito à rescisória corresponde ao dever estatal de prestar jurisdição, solucionando a lide, na exata medida da precomposição do conflito de interesses pelo direito objetivo. Se essa prestação traz, em si, a marca de desvio in procedendo ou in iudicando - que o sistema jurídico tenha 
por presuposto de rescindibilidade, a ele cede, durante certo tempo, a incolumidade da coisa julgada que, durante esse lapso de tempo, pode ser desconstituída, mediante prestação jurisdicional a isso, especificamente, destinada. A res iudicata perene por conceito - fica, temporariamente, sujeita a reexame, precipuamente destinado, ou a confirmá-la, ou a desfazê-la, segundo o iudicium rescindens seja, ou de rejeição, ou de acolhimento.

Essa estrutura mostra como e porque o tempus é elemento essencial ao direito de rescindir sentenças firmes, de que decorre a chamada pretensão à rescisão que, sem ele, seria ineficaz, porque a imutabilidade da sentença que transita em julgado é a isso simultânea, não deixando espaço para o pedido rescisório. $\mathrm{Ou}$ o direito à rescisão é concebido com prazo para o seu exercício, ou não será direito. Daí a essencialidade do elemento temporal de exercício que, integrando a estrutura mesma do direito, não pode ser eliminado, total ou parcialmente, sem afetação do próprio direito que só o prazo faz adquirido, na medida do disposto no $\S 2 .^{\circ}$, do artigo $6 .^{\circ}$, da vigente Lei de Introdução ao Código Civil.

Por isso a lei nova não pode modificar, senão para o futuro, o prazo de exercício do direito a rescindir sentenças trânsitas sem julgado. A isso se há de acomodar, pois, a regra do art. 1.211, do Código de Processo Civil, por respeito ao disposto no $\S 3 .^{\circ}$, do art. 153, da Constituição vigente. Com isso se atende ao elemento sistemático de que não prescinde a interpretação das leis, segundo o magistério de Savigny (Sistema - trad. italiana de Scialoja, Torino, 1886, vol. I, pág. 222) e o posicionamento exato de POTHIER: "Une disposition doit s'entendre plutôt dans le sens où elle peut avoir un effet, que dans celui où elle n'en aurait pas" (Oeuvres - Paris, 1861, tome 1. er - pág. 456)

Se o direito de propor ação rescisória não tivesse a estrutura que apontamos, seria aceitável a idéia de que o prazo não é, dele, "uma conseqüência necessária e inseparável", como entendera, no caso da consulta, o acórdão rescindendo. Ademais, exatamente porque excepcional a permissão de se demandar, em prazo fatal, o desfazimento da coisa julgada, é que o tempus para isso fixado integra o direito de pleiteá-lo. De outro lado, se a coisa julgada envolve "interesses indisponiveis, de natureza eminentemente publica", a brecha neles aberta, com a adoção, pelos sistemas jurídicos, da ação rescisória, também resulta de interesse público na realização exata do direito objetivo que só não tem o traço da indisponibilidade 
porque a certeza jurídica estabelecida pela res iudicata atende ao objetivo de eliminação dos conflitos de interesse que pertine aos litigantes.

Se fosse exata a tese de que a lei nova pode reduzir prazo de decadência para exercício de direito já adquirido, chegar-se-ia ao absurdo de que pode ela eliminar o próprio direito, estabelecendo prazo novo que impeça o seu exercício. As soluções de conveniência que, para esses casos, se procura ora aplicando a lei antiga, ora a lei nova, implicam, data maxima venia, fuga ao problema que não comporta tais acomodações. Ademais, a circunstância de serem as leis processuais de aplicação imediata, alcançando os feitos pendentes, essa concerne à parte formal de sua disciplina - não à material que nelas também existe.

Em plano amplo, assinala PAUL RoUBIER, ao estabelecer a diferença entre o efeito retroativo e o efeito imediato das leis: "La base fondamentale de la science des conflits de lois dans le temps, c'est la distinction de l'effet rétroactif et de l'effet immédiat de la loi. Cela parait une donnée très simple: l'effet rétroactif, c'est l'application dans le passé; l'effet immédiat, l'application dans le présent; il ne paraît pas très malaisé de définir et de distinguer ces deux moments de la durée. Si la loi prétend s'appliquer à des faits accomplis (facta praeterita), ello est rétroactive; si elle prétend s'appliquer à des situations en cours (facta pendentia), il faudra établir une séparation entre les parties antérieures à la date du changement de législation, que ne pourraient être atteintes sans rétroactivité, et les parties postérieures, pour lesquelles la loi nouvelle, si elle doit s'appliquer, n'aura jamais qu'un effet immédiat; enfin, vis-à-vis des faits à venir (facta futura), il est clair que la loi ne peut jamais être rétroactive." (Les Conflits de Lois dans le Temps — Sirey, 1929 — Tome premier — pág. 371)

"Touts les lois - diz, mais adiante, Roubier sont faites, en effet, pour déterminer un certain nombre de situations juridiques au profit ou à l'encontre de certaines personnes; c'est donc dans leur action vis-à-vis des situations juridiques passées, présentes ou futures que se résume leur action dans le temps." (Ob. e vol. cit., pág. 378)

Essa ação, em face de situações jurídicas pretéritas, vincula-se à sua admissibilidade pelo sistema jurídico de que se trate.

Entre nós; desde a Constituição Imperial de 25 de março de 1824 , artigo $179, \S 3 .^{\circ}$, até a atual, artigo $153, \S 3 .^{\circ}$ - salvo 
o hiato paraconstitucional de 1937 - vigora o princípio da irretroação da lei, dirigido ao próprio legislador, mais forte, portanto, do que o texto do art. $3 .^{\circ}$, da antiga Introdução ao Código Civil, atual art. $6 .^{\circ}$, sem a rigidez própria das normas constitucionais. "O legislador ordinário podia alterar, quando quisesse, tais definições, mas, pela natureza das coisas, a ciência do direito é que diz a última palavra, embora elas mesmas só fossem conceitos de direito substancial. O legislador constituinte por isso mesmo se afastou e só reteve o que corresponde à parte inicial do art. $3 .^{\circ}$ da Introdução ao Código Civil e, depois ao art. $6 .^{\circ}$ do Decreto-lei n. ${ }^{\circ} 4.657$, de 4 de setembro de 1942, que é regra de sobredireito." (PONTES DE MIRANDA Com. à Const. de 1967, Tomo V, pág. 65) Princípio vetusto e salutar, porque a "irretroatividade defende o povo; a retroatividade expõe-no à prepotência", como observa PONTES DE MIRANDA. (Ob. e tomo cit, pág. 20)

Aludindo ao texto da Constituição de 1967, diz Pontes que o conceito de direito adquirido é conceito do plano da existência: se ato jurídico começa a existir, aqui e agora, é porque o ato entrou no mundo jurídico aqui e agora, e a sua juridicidade é a coloração que lhe deu o sistema jurídico, tal como aqui e agora ele é. $\mathrm{O}$ direito adquirido é o direito que nasceu a alguém. O conceito é conceito do plano de eficácia, porque todo direito é efeito, como são efeitos todo dever, toda pretensão, toda obrigação, todas as ações e todas as exceções. Deve ter havido, antes, fato, que entrou no mundo jurídico, em certo lugar e em certo momento, embora pudesse não ter sido ato, do qual se haja irradiado o direito. Por onde se vê que o legislador constituinte só aludiu ao direito, brevitatis causa, isto é, para não ter de mencionar todas as espécies de fatos jurídicos de que podem emanar direitos, deveres, pretensões, obrigações, ações e exceções. Em verdade, a lei nova não incide sobre fatos pretéritos, sejam eles, ou não, atos, e - por conseguinte não pode "prejudicar" os direitos adquiridos, isto é, os direitos já irradiados e os que terão de irradiar-se. Note-se bem: "terão de irradiar-se". (Ob. e tomo cit., pág. 60)

Note-se que a jurisprudência de nossos tribunais é uníssona, a esse respeito, em face da aplicação de leis anteriores e sob o império da Constituição Federal de 1946 que, em seu art. $141, \S 3 .^{\circ}$, consagrava o mesmo princípio da irretroação das leis, Confira-se, nesse sentido os v. julgados que se encontram na Revista dos Tribunais, vol. 192, págs. 130 e 134; vol. 193, págs. 319, 364, 833, 843, 885 e 937; vol. 194, págs. 799 e 824 ; vol. 195 , pág. 395 ; vol. 196 , págs. 205 e 263 ; vol. 197, 
pág. 197 ; vol. 198 , pág. 147 ; vol. 202, pág. 404 ; vol. 209, pág. 159 ; vol. 239 , pág. 561 ; vol. 243 , pág. 449 ; vol. 325 , pág. 494.

A distinção entre normas de direito material e normas de direito processual é, pois, significativa, em face daquele irradiar-se que tanto pode ocorrer no plano das primeiras, como no âmbito das segundas, homogênea ou heterogeneamente. Se o direito adquirido é material processual, a irradiação será homogênea, no próprio plano em que o ato ocorreu; se se verificar no plano pré-processual, a irradiação pode dar-se nesse mesmo plano e, eventualmente, no processual. Neste último caso, será heterogênea. De qualquer sorte, sob o prisma do direito intertemporal, considera-se a aquisição do direito no plano em que tenha ocorrido e segundo a disciplina, para ele, então vigente.

Claro que o caráter continuativo da relação jurídica processual e a especificação de etapas do procedimento postulatória; instrutória; de debate, sentencial, de impugnação para reexame - propicia ao legislador ordinário um sistema de normas de direito intertemporal que as considere, se com isso não afrontar o princípio constitucional da irretroação, para o que é essencial que se ressalvem os direitos processuais adquiridos.

Neste particular, expressivo o art. 158, caput, do Código de Processo Civil vigente: "Os atos das partes, consistentes em declarações unilaterais ou bilateriais de vontade, produzem imediatamente a constituição, a modificação ou a extinção de direitos processuais."

Os direitos daí resultantes não podem ser afetados por disciplina processual nova, não obstante o princípio da sua aplicação imediata.

Embora se configure no âmbito do direito público, "a lei nova - como assinala o Prof. GALENo LACERDA - não pode atingir situações processuais já constituídas ou extintas sob o império da lei antiga, isto é, não pode ferir os respectivos direitos processuais adquiridos. 0 princípio constitucional de amparo a esses direitos possui, aqui, também, plena e integral vigência". (O Novo Direito Processual Civil e os Feitos Pendentes - Rio, 1974, pág. 13)

Em suma: sem embargo de lei processual nova, o direito de rescindir sentenças firmes que se tenha adquirido no regime da lei anterior, de natureza material processual, permanece incólume e pode ser exercido, opportuno tempore, enquanto não se escoe o prazo que, com a sua aquisição se iniciou. 